\title{
Multimodality: An Invitation
}

\author{
Samuel Gerald Collins , Matthew Durington , Harjant Gill
}

First published: 12 January 2017

https://doi.org/10.1111/aman.12826

This section used to be called Visual Anthropology. Its new name-Multimodal Anthropologies—reflects changes in the media ecologies we engage as anthropologists, changes that have broadened our perspective to include other forms of media practice, while remaining inclusive of visual anthropology. Many of these changes can be linked to three developments: (1) the (relative) democratization and integration of media production; (2) the shift toward engagement and collaboration in anthropological research; and (3) the dynamic roles of anthropologists vis-à-vis both the profession and the communities in which they work. Together, these changes suggest a new framework, multimodal anthropology, by which we mean not only an anthropology that works across multiple media but one that also engages in public anthropology and collaborative anthropology through a field of differentially linked media platforms. This is not, however, a decisive "break" with the past. Many of us already practice multimodal anthropology (Collins and Durington 2014; Cool 2014; Edwards 1997; Pink 2011; Postill 2011; Stewart 2013). When we consider the different opportunities and possibilities for engaging with ethnographically intended media in the age of diverse tools and platforms, we see multimodal anthropology. When we look at the transmedia installations of Ethnographic Terminalia, we see articulations of multimodal anthropology. Multimodal anthropology is also encapsulated within the numerous visual, aural, and tactile media that anthropologists produce, post, and share - the growing decoupage of social media that is one symptom of a changing anthropological practice. Multimodal practice is not limited to self-identification as a visual anthropologist. Rather, it encompasses this subdiscipline and also invites practitioners from within and outside anthropology. Finally, we see multimodality in the ways communities of non-anthropologists interact with us, from para-anthropological productions to critique and commentary. In what follows, we lay out our vision and ever-expanding areas of interest for this section as we explore the transformative potentialities of the multimodal. It is meant less as a provocation than an invitation to submit works that engage multimodal possibilities. 


\section{PREAMBLE}

Multimodality describes the arc of anthropological media through contemporary society. It evokes the heterogeneities of anthropological research across multiple platforms and collaborative sites, including film, photography, dialogue, social media, kinesis, and practice. At its core, multimodal anthropology acknowledges the centrality of media production to the everyday life of both anthropologists and our interlocutors. It demands that we reflect on this multiplicity while working to engage and collaborate along media forms our interlocutors find relevant to their lives. A multimodal approach extends not only to the research anthropologists do leading up to media production but also to the afterlife of anthropologically intended media. It implicates the relationships between anthropologists and networked publics formed through dissemination, as well as the discussions and debates that media engender. Mutimodality insists that we look to media practice within our research and scholarship, and simultaneously pay attention to how our work is often mediated through institutions fraught with ethical dilemmas and continuous negotiations. It invites us to explore how contemporary media forms, producers, and communities are embedded in systems of highly unequal capital accumulation.

A multimodal anthropological approach is both descriptive and prescriptive. It characterizes the way people work and conduct research in the contemporary world, and implores us to conceive of anthropological research and scholarship beyond the finished, reified products of fieldwork or labwork: an article, a book, an ethnographic film, a photo essay. Instead, we are encouraged to engage in varying processes of knowledge production that often lead to multiple outcomes. Prescriptively, multimodal anthropology asks that we take these outcomes and processes seriously as meaningful interventions that nudge anthropology into more collaborative, innovative, and reflexive directions. We appreciate outcomes but also look to emphasize the knowledge that comes from recognizing and analyzing the process in getting these outcomes, and to explore varying methodologies in their own right.

Above all, a multimodal anthropology does not attempt—or desire — to supplant visual anthropology. Rather, it seeks to include traditional forms of visual anthropology while simultaneously broadening the purview of the discipline to engage the variety of media forms that exist today.

\section{MULTIMODALITY IN ANTHROPOLOGICAL PRACTICE}

On their way to producing anthropological media, anthropologists weave a complex skein of trace media behind them: from social media posts to relationships built with communities; to hastily recorded sound bites and photographs taken to help us remember specific details; to rough cuts and early edits of films; to varied exchanges and quid pro quo arrangements where field researchers produce recordings, photographs, and film at the behest of the community (Jackson 2004). These traces reveal the complexities of how our interlocutors engage with media as well as the processes through which we conduct research and arrive at particular understandings. Previously, materials that did not end up in the final account of our research were relegated to a dusty bookshelf or a forgotten cardboard box somewhere in our offices. In an age of accelerated media proliferation, these networked forms of media are rendered more visible and, paradoxically, at a time when 
they might seem ephemeral, even more permanent. The trail of shared, collaborative media that our research and practice produces continues as a series of traces that adumbrate the anthropological engagement, a networked archive that twists around the final products of ethnography like snakes along the mythical caduceus. Multimodal anthropology refocuses our attention on these pre- and post-fieldwork encounters, compelling us to follow these complex networks back through the various collaborations and reciprocities that make up engaged anthropology today. While some of these (para)productions might be more quantifiable than others in terms of the value our institutions assign to them, they still connect to our interlocutors in meaningful ways that demand our attention as engaged anthropologists committed to supporting and giving back to communities we represent.

\section{MULTIMODALITY THROUGH COLLABORATIVE MEDIA}

The relationships and rapport that develop through anthropological fieldwork were either ignored or minimally addressed in historical anthropology. Perhaps it is the black-and-white photo of the lone anthropologist talking to an informant sidelined to the ephemera of fieldwork practice or the reflexive gesture of a hand reaching from behind the camera to greet that disrupted these vestiges of descriptive anthropology. Disruptions to the intellectual authority of the anthropologist (colonial, Western, racial) were "accidents" of the anthropological engagement. Over time the authority of the anthropologist was rivaled by the recognition of local knowledge production, and the roles of researcher and research subject began to be contested. This can be witnessed through changes in the nomenclature itself as reified "subject” moves to "participant," “collaborator,” or even “coauthor.” From participatory action research to participatory cinema, the reflexive engagement and critique of the primary role of the anthropologist have fashioned a different type of methodology and outcome (Gubrium, Harper, and Otanez 2015). Multimodality necessitates and demands a revelation of the collaborative nature of anthropology and informs the various media produced through these encounters. New forms of media shared through various networks such as social media would not even exist without collaboration. Therefore, to overlook the collaborative nature of anthropological work would be misrecognition of multimodal anthropology.

The inclusion of reflexivity in anthropological practice is one way to recognize the collaborative nature of anthropological media (Ruby 1982). The creation of anthropological media- a photograph, film, or textinvolves ideological closure, where the institutions and relations that overdetermine the production of media are obscured by the text as an ideological artifact. Occasionally, over the decades, scholars have (sometimes heroically) regrafted these ideological processes in moments of reflexivity. But these moments of transparency are ex post facto and bear their own ideological weight amidst a postmodernism that looks both like a break and a continuation of the status quo. Foregrounding the collaborative nature and ethos of anthropological work disrupts overdetermination.

\section{EDUCATING ANTHROPOLOGISTS IN MULTIMODALITY}

Students learning anthropology arrive in our classrooms already proficient in the language of media. For most, engaging and collaborating through media comes almost as second nature. In times past, they have learned to "cut the network" (Strathern 1996) through published works assigned to them that may have arisen 
through collaborative processes, but are presented typically as single-authored texts, films, or photographs. A multimodal approach to teaching anthropological research methods demands that we highlight anthropology as a "work in progress" that traverses multiple, collaborative platforms. While the conventional educational experience will undoubtedly continue to privilege finished, edited media, a multimodal approach to learning demands that our students think through the politics and vicissitudes of indigenous media and social media, gallery shows, performances, designs, apps, games, makerspaces, diagrams, and prototypes, in addition to sites of para-anthropology negotiated on a variety of platforms. These too are components of anthropological methods in a multimodal age. On one level this call for expansion of anthropological curricula might seem like an ambitious undertaking. Yet multimodality is only about recognizing the ever-present "messiness" of the anthropological encounter, with the acknowledgment that much of this complexity is rendered more and more transparent through the ubiquity of media practices. It demonstrates that the anthropological field site and the work of anthropology itself is never static or ossified, but is constantly subject to change. As a pedagogical intervention, multimodal anthropology asks students to reflect on media ecologies in which they are already imbricated, and challenges them to engage these forms and practices in innovative ways without compromising our ethical responsibilities toward our interlocutors and the communities we represent.

\section{EMERGENT MULTIMODALITIES}

The framework of multimodal anthropology also keeps open a space for other forms of media engagements that will emerge in the near future, with the understanding that some of the multimodal media we now practice will be rendered obsolete. It elides the critique of technological determinism by allowing a constant space for new technologies and modes of dissemination to be recognized and welcomed by necessity. Given the accelerations of transnational capitalism, media platforms supplant each other with a dizzying rapidity that seems designed to undermine critique in the age of spectacle. But this is synecdoche for anthropology as a whole, with its discourse continually threatened with either absorption into the capitalist image machine or insouciance from public discourse. Here, the exposure of multimodality to the vicissitudes of capital accumulation, commodification, transnational circulation, and spectacle serves to critically locate the anthropological enterprise within a political-economic apparatus that the discipline as a whole has paid scant attention to.

A multimodal approach demands that we consider the ways in which current media practices are embedded in global systems of inequality. One of the exciting (albeit unintended) consequences of new media for multimodality is that the negotiations around media-related practices in anthropology, the uncertainties, and the processes of dialogue and exchange are more visible on every level. In other words, all of the traces of anthropological research that fall outside of finished media come racing back-the return of what is repressed in anthropological research. Similarly, future media will reveal new forms of exploitation and, inevitably, new challenges for anthropologists. Each of these new challenges will undoubtedly generate new spaces for reflection and critique. Just as moves toward open access and Creative Commons licensing have generated new questions about the ethics of publishing our work behind paywalls, so will future media precipitate new and unknown perspectives on inequalities latent in the anthropological encounter. 


\section{MULTIMODAL SCHOLARSHIP CIRCULATION}

A multimodal approach to anthropological research and scholarship also demands the questioning and inevitable decentering of the hierarchies of scholarly production, within which book-length monographs, journal articles, and (more recently) feature-length ethnographic films have been privileged. A commitment to a multimodal anthropological future includes the recognition that the flow of ideas and scholarship does not necessarily need to follow the familiar, fairly narrow, and increasingly crowded path to publication that requires us to seek legitimization from high-impact journals, exclusive academic presses, and premier film festivals. Multimodal anthropology emerges partly out of its practitioners' frustrations with the inability of these limited venues to keep up with innovation and expansion in anthropology, and to adequately reflect the changing landscape and influence of emerging media technologies on anthropologists and our interlocutors' everyday lives. In doing so, the project of multimodal anthropology is also a provocation, encouraging researchers to consider innovative approaches to research, learning, and knowledge production without the anxiety of being dismissed as extraneous or frivolous.

American Anthropologist's endorsement of a more multimodal future should be seen as a commitment to the egalitarianizing of scholarly production within our discipline by expanding the disciplinary boundaries to include forms of scholarship that have traditionally struggled to gain a foothold in anthropology. It is commendable that the traditional mechanisms of gatekeeping are now opening up to multimodal possibilities. Such an ambitious endeavor is certain to pose new challenges when it comes to the reviewing and vetting processes we currently have in place to legitimize our research, sanctioned by our discipline and our institutions. In some sense, this concern with legitimization confronting multimodal anthropology is perhaps a greater challenge than the inclusion of diverse perspectives and approaches to research and knowledge production, and there exists no effortless solutions. But a commitment to a multimodal anthropological future also demands a commitment to working through and overcoming these challenges in a synergetic way, coming up with innovative solutions that build on existing strengths of our discipline as well as nudging our institutions toward recognizing the value of a multimodal-inclusive future.

\section{NEGOTIATING THE TERRAIN OF MULTIMODALITY}

What does it mean to be a multimodal academic? For many (if not most) of us, it means that faculty pursue multimodal work "on the side" of their academic productions. This can work if the anthropologist uses multimodal scholarship as a stepping stone toward more conventional forms of scholarly dissemination, but this form of self-censorship also limits the potential of what multimodality can be. For practitioners of visual anthropology, this is a familiar process, with their work only recently gaining academic acceptance in many institutions. Yet the barriers facing multimodal scholarship are even more manifold. Because multimodal anthropology is at its core a challenge to the ideological closure of research into the discrete work of a single author, there are many unresolved dilemmas for anthropology faculty. Perhaps, this is the point.

While anthropologists have yet to grapple with the challenge of a multimodal professorate, other disciplines have begun to reformulate rules of promotion and tenure. The American Sociological Association, for example, has just released a report on social media in academic careers, “"What Counts? Evaluating Public 
Communication in Promotion and Tenure” (McCall et al. 2016), that takes these digital platforms seriously as means of scholarly engagement in their own right. That said, the ASA report confines its discussion to social media as a tool to "disseminate research findings" (4) — in other words, as a proxy for or a supplement to print-based scholarship that is still at the core of promotion and tenure decisions in the academy. This is far too limiting and lacks imagination. If any field has the capacity to engender a multimodal practice and set of productions, it is anthropology. We should be the first to legitimate these notions both as a discipline and practice.

In other words, the ASA report recognizes social media at the cost of ignoring other dimensions of media that enfold our academic work. Consider social media as more than platforms for dissemination. First, social media have become a means of research—-forums where research and scholarship are formulated, negotiated, and organized. Second, social media have become sites of collaborative media production, places where media have flowed between anthropologists, interlocutors, and communities. These processes defy the easy assignation of authorship but also suggest a more egalitarian form of knowledge production. Finally, social media (by definition) support forms of dissemination that are simultaneously reproductions through remix, recontextualization, and the secondary production of added media content. That is, media on social media platforms are dynamic and protean in a way that other forms of scholarly dissemination (even those that lay claim to reflexivity) may fail to be.

Rather than resolve into a conventional "genre" of scholarly dissemination, we believe that multimodal platforms will: (1) continue to proliferate through a variety of commercial and noncommercial applications; and (2) that these developments will continue to call into question definitions of scholarship and will continue to problematize the position of the anthropologist amid complex relations of collaboration, multiple authorship, remixing, and porting across fields of inequality and difference (Kelty 2008).

\section{EXAMPLES OF MULTIMODALITY IN CURRENT WORK}

Multimodal anthropology can come from a variety of places and take many forms. Here are a few that we are working on.

Maybe multimodal anthropology can be a game that challenges the ethics of anthropologists and students of anthropology by co-opting a popular card game (Figure 1). 


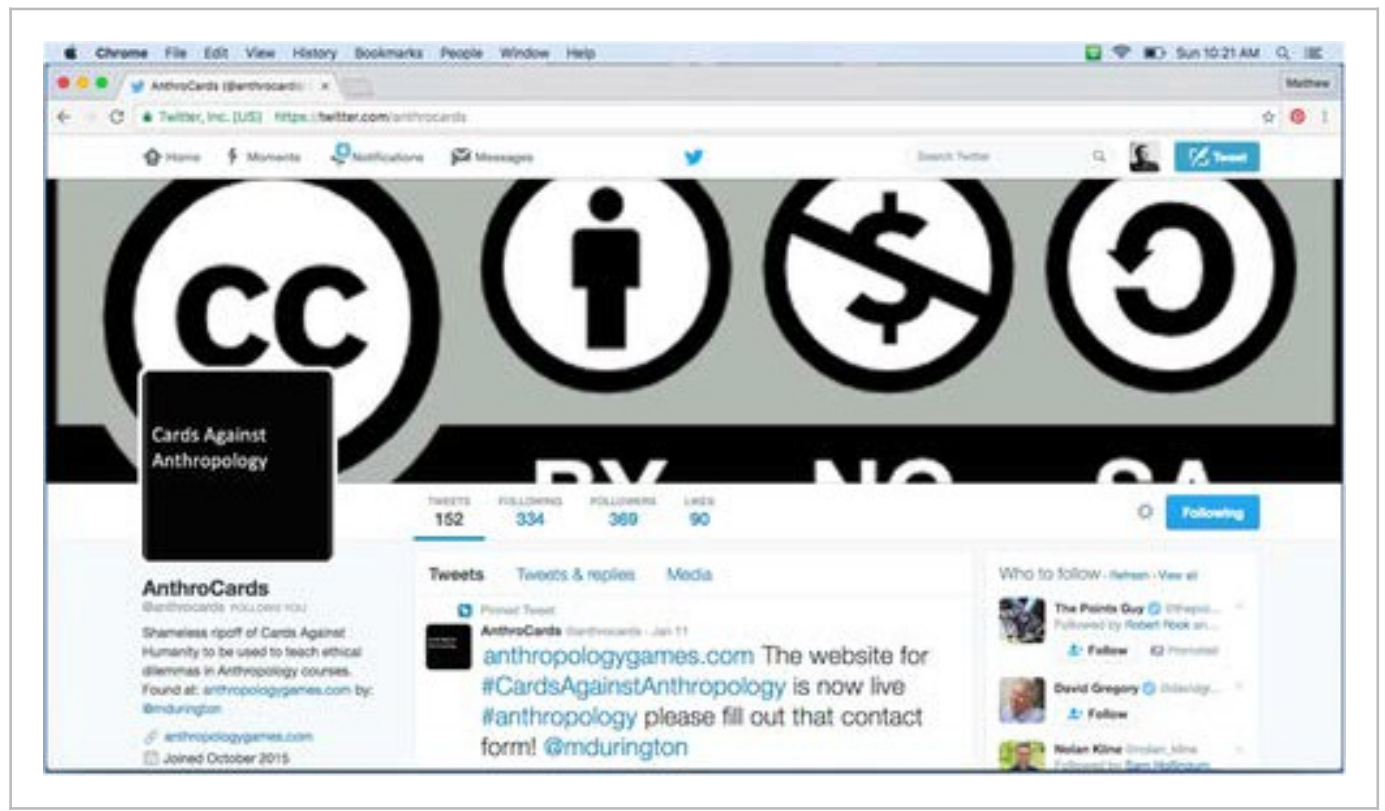

\section{Figure 1}

A screenshot of the Cards Against Anthropology Twitter page @anthrocards. (Screenshot taken by Matthew Durington) [Color figure can be viewed at wileyonlinelibrary.com]

Perhaps it can be a geolocating mobile app walking tour informed by anthropological fieldwork (Figure 2).

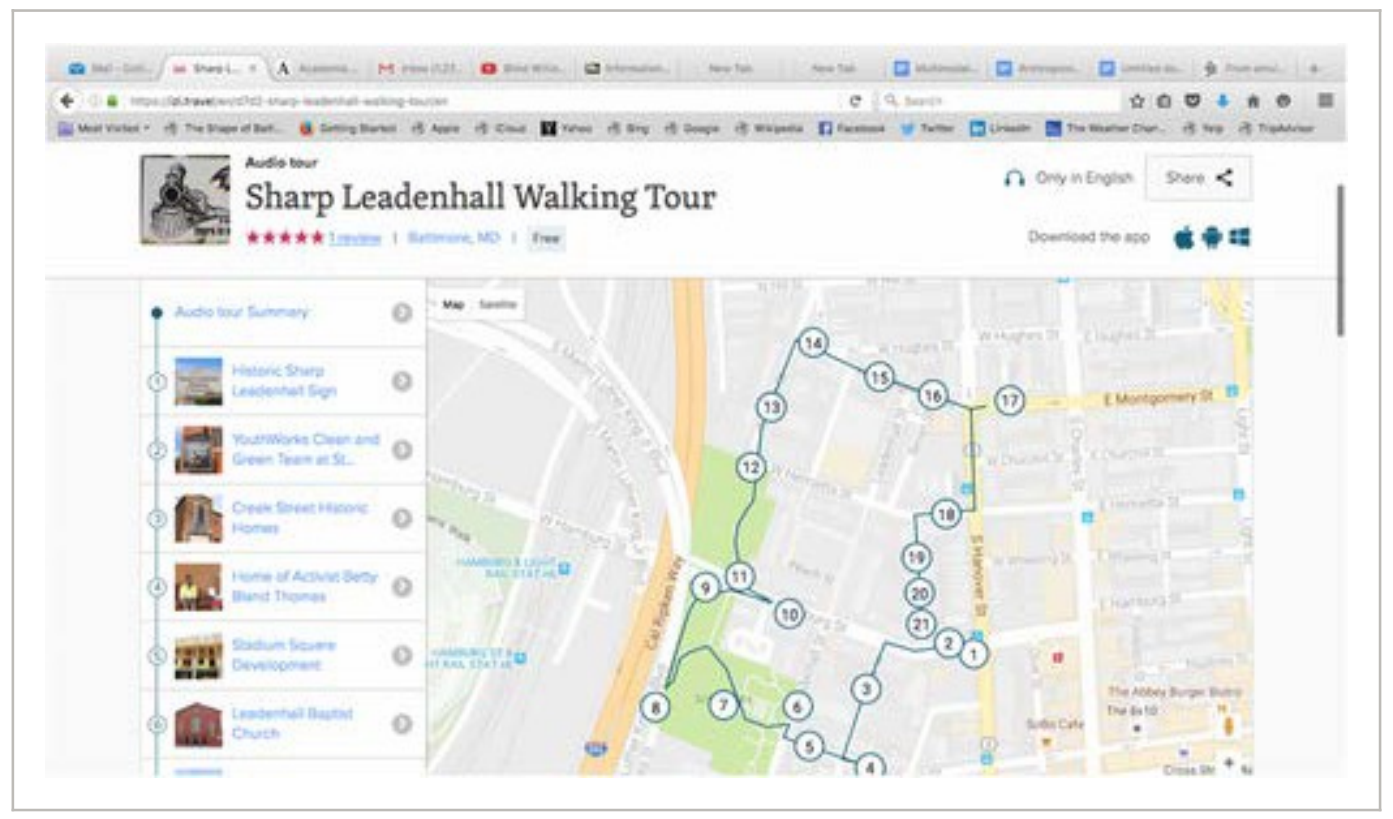

\section{Figure 2}

Screenshot of izi.travel app. (Screenshot taken by Samuel Collins) [Color figure can be viewed at 
Or we can locate the multimodal within a distribution strategy for an ethnographic film (Mardistan/Macholand) that challenges censor boards in India by simultaneously circulating the uncensored versions online on open-access platforms as the censored version is telecasted on Indian national television (Figure 3).

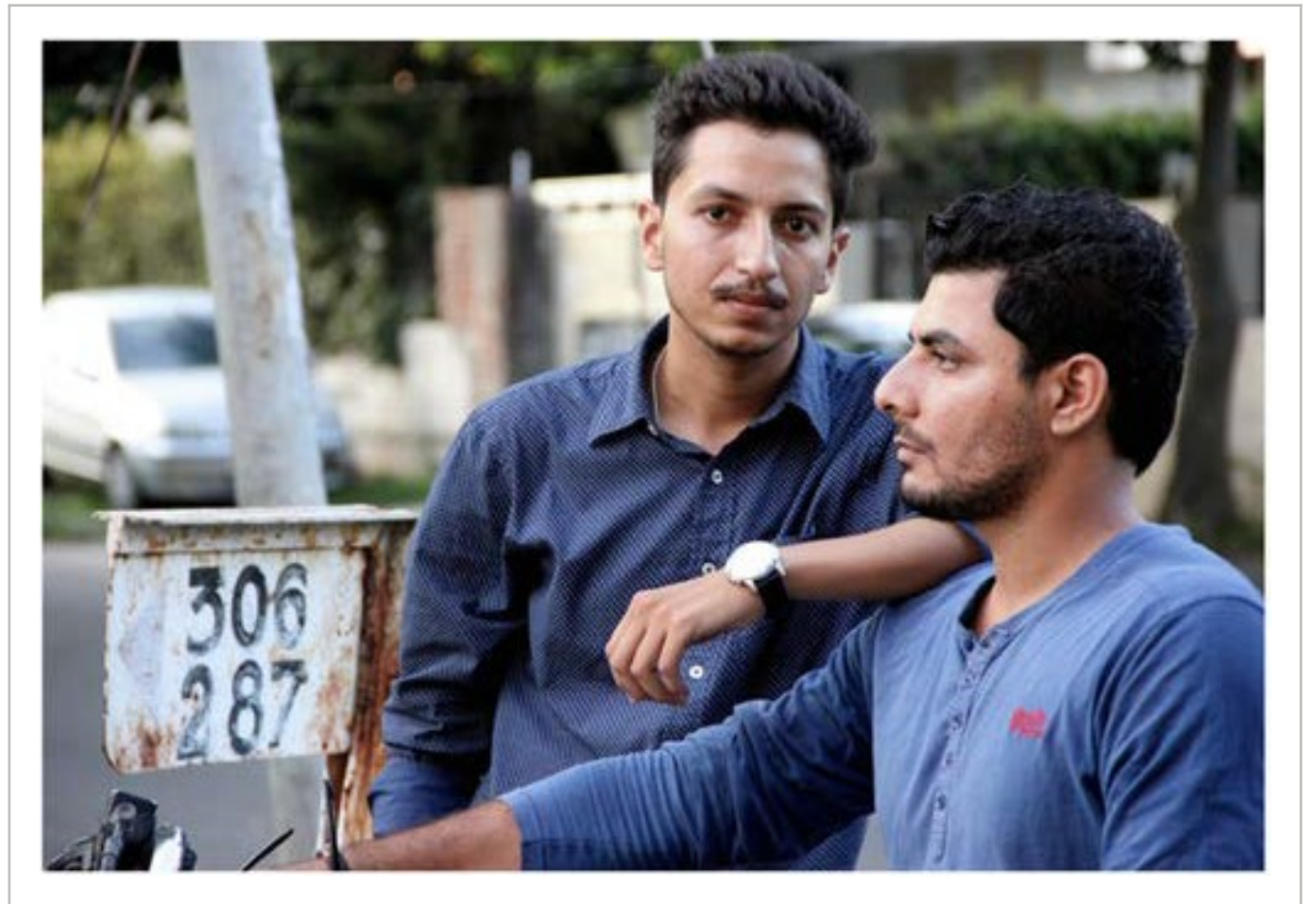

\section{Figure 3}

Still from Mardistan/Macholand. (Gill 2014) [Color figure can be viewed at wileyonlinelibrary.com]

\section{AN OPEN INVITATION TO JOIN IN AND BE PART OF THE MULTIMODAL MOVEMENT}

As we chart this terrain toward a new horizon in anthropology, we hope that you join us and participate in shaping the future for our discipline that we have outlined above. Commitment to multimodalityincorporating multimodal approaches in our research, practice, and dissemination of our scholarship—does not necessitate the acquisition of an entirely new skill set, or investment in the latest high-tech gadgets and 
media equipment, or even membership in a particular group or society. Instead, a multimodal approach implores us to consider carefully the kinds of practices that are already present in how we have been "doing" anthropology. We hope that the shift from visual anthropology to Multimodal Anthropologies signals a tearing down of outdated disciplinary boundaries that have prevented us from embracing innovative ideas and approaches in our research and scholarship. By no means should the articulation of a multimodal future, as laid out in this essay, be seen as an attempt to draw new boundaries. Instead, we intend to begin an open dialogue about the future of our discipline, and we invite everyone to join in this ongoing conversation. 